\title{
Asthma treatment with a new corticosteroid aerosol, budesonide, administered twice daily by spacer inhaler
}

\author{
H V FIELD, P M A JENKINSON, M H FRAME, AND J O WARNER \\ Brompton Hospital, Cardiothoracic Institute, London, and Astra Clinical Research Unit, Astra \\ Pharmaceuticals Limited, St Albans, Hertfordshire
}

SUMMARY In a double-blind crossover trial a new corticosteroid aerosol, budesonide, delivered by spacer inhaler twice daily, was found to be at least as effective in controlling childhood asthma as beclomethasone dipropionate administration four times a day. The twice daily dosage schedule of the new preparation offers considerable advantages for compliance with therapy in schoolchildren. Previous studies have shown that lung deposition of aerosol is increased by the use of a tube spacer between the pressurised aerosol inhaler and the mouth. This technique of administration may improve the efficacy of corticosteroids in the treatment of asthma.

Attention has recently been focused on systems used to generate and deliver aerosols to the respiratory tract in the treatment of asthma. A hollow tube spacer between pressurised aerosol inhaler and the mouth enhances the bronchodilatation produced by terbutaline. ${ }^{1}$ So far this system has not been available for administration of steroid aerosols. A new topically active steroid, budesonide, has been developed that can be delivered via the spacer inhaler. It has been shown in short-term studies to be as effective when administered twice daily to adults as beclomethasone dipropionate (BDP) administered four times daily. ${ }^{2}$ We compared the efficacy of this preparation with BDP in a double-blind crossover trial in children with asthma.

\section{Patients}

Thirty-one children (12 girls and 19 boys) aged between 4 and 14 years were enrolled from a paediatric asthma clinic. Each had fairly severe asthma requiring regular inhaled steroid prophylaxis. In 27 the condition had failed to improve despite treatment with sodium cromoglycate: 10 had been admitted to hospital with exacerbations of the asthma in the last year and, of the 22 tested, 21 had positive skin tests to common allergens. The condition of all improved on introduction of inhaled steroids and none had received oral or parenteral steroids in the month before the trial.

Seventeen were taking the BDP by aerosol and 14 by rotahaler, the mean period of use before the trial being $16 \cdot 2$ (range 1 to 48 ) months.

\section{Methods}

The children were randomly allocated to one of two treatment groups. The first took budesonide $200 \mu \mathrm{g}$ twice daily and placebo BDP four times daily for one month, followed by placebo budesonide twice daily and BDP $100 \mu \mathrm{g}$ four times daily for a further month. In the second group the order was reversed. The BDP was administered in the same form as used by the child before the trial. The budesonide was administered by pressurised aerosol with a spacer inhaler. All children were judged to use their inhalers adequately.

Each child was assessed in the clinic before the trial and at the end of each treatment period. Evaluation was by clinical history, examination, and a flow volume curve before and after a dose of inhaled bronchodilator. The flow volume curves were recorded using a Hewlett Packard digital pneumotachograph (model 47303A1) and an XY plotter (model $7041 \mathrm{M}$ ) with one second time marker. The best of three curves was used to calculate forced expiratory volume in one second $\left(\mathrm{FEV}_{1}\right)$, forced vital capacity (FVC), peak expiratory flow rate (PEFR), and expiratory flow rates at $50 \%$ and $25 \%$ of vital capacity $\left(\mathrm{V}_{\max } 50\right.$ and $\left.\mathrm{V}_{\max } 25\right)$. Results were expressed as a percentage of expected for height. ${ }^{34}$

Each patient kept a diary card to record the severity of night cough and wheeze, day wheeze, and exercise limitation on a scale of 0 to $3(0=$ none, $1=$ mild, $2=$ moderate, $3=$ severe). The number of extra doses of bronchodilator required and the twice daily PEFR measured on a Wright mini peak flow meter were also recorded. 
A short Synacthen test was used as a measure of adrenal function before and at the end of the trial. At the same time a full blood count and differential white cell count, urea, electrolytes, creatinine, and liver function tests were done.

The Wilcoxon rank paired test was used to compare the results from the two treatment periods on each patient. The trial had the approval of the hospital ethical committee and informed consent was obtained from the parents.

\section{Results}

Thirty-one children entered the trial but 4 dropped out during the first month, two because they no longer wished to continue, and two because of acute exacerbations of asthma, requiring hospital admission. One of each pair came from each treatment group.

Of the 27 children completing the study, 15 used the pressurised aerosol and 12 the rotahaler preparation of BDP. There were no significant differences in any evaluation between these two modes of delivery during the trial, and the results were therefore assessed together.

The FEV $1, F V C$, PEFR, $V_{\max } 50$, and $V_{\max } 25$ measured at the end of each month showed no significant differences. The morning and evening PEFRs and diary card symptom scores for the second 2 weeks of each month were ccmpared and differences did not reach significant levels (Figure), although there was a consistent tendency towards greater benefit from budesonide (Table). Analyses took treatment order into account, and there was no significant difference between any 2-week period throughout the trial.

All the routine blood tests were normal apart from an eosinophilia $\left(>0.5 \times 10^{9} / 1\right)$ in 15 patients.
80

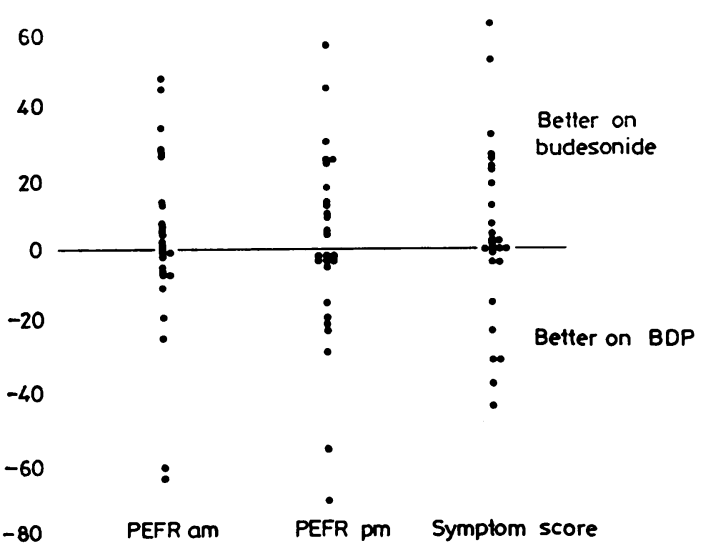

Figure Circles represent differences in PEFR (\% predicted), and absolute symptom scores between the last 2 weeks of each treatment, for each patient.

There was no significant change in any parameter by the end of the trial. None of the basal cortisol levels measured at the beginning and end of the trial was subnormal $(<150 \mathrm{nmol} / \mathrm{l})$. Plasma cortisol responses to Synacthen did not alter significantly after drug treatment in either treatment group. There were 18 normal responses on both occasions (increase $>190$ nmol/1); 5 marginally subnormal responses at the beginning of the trial, but normal at the end; 3 normal on the first occasion, but not repeated; and 1 child with a subnormal response at the end of the study (basal 500 increasing to $600 \mathrm{nmol} / 1$ ).

For the purposes of the trial the dose of BDP was doubled in 12 of the children; 8 of these showed an improvement in the flow volume curves while on the higher dose.

Table Lung function tests and symptom scores measured daily at home or during clinic visits

\begin{tabular}{|c|c|c|c|c|}
\hline Measurements & $\begin{array}{l}\text { Budesonide } \\
\left(\text { mean }^{*} \pm S D\right) \\
\%\end{array}$ & $\begin{array}{l}\text { No of patients } \\
\geqslant 10 \% \text { better } \\
\text { with budesonide }\end{array}$ & $\begin{array}{l}B D P\left(\text { mean }^{*} \pm S D\right) \\
\%\end{array}$ & $\begin{array}{l}\text { No of patients } \\
\geqslant 10 \% \text { better } \\
\text { with BDP }\end{array}$ \\
\hline Mean morning PEFR & $90 \cdot 3 \pm 20 \cdot 5$ & 7 & $87 \cdot 4 \pm 30 \cdot 8$ & 4 \\
\hline Mean evening PEFR & $93 \pm 21 \cdot 3$ & 8 & $92 \cdot 1 \pm 35 \cdot 3$ & 6 \\
\hline Symptom score & $13 \cdot 6 \pm 16 \cdot 5$ & 9 & $17 \cdot 2 \pm 19 \cdot 3$ & 6 \\
\hline \multicolumn{5}{|l|}{ Clinic } \\
\hline $\mathrm{FEV}_{1}$ & $83 \cdot 4 \pm 22 \cdot 9$ & 7 & $78 \cdot 5 \pm 25 \cdot 1$ & 6 \\
\hline FVC & $99 \cdot 7 \pm 17 \cdot 5$ & 4 & $100 \cdot 3 \pm 17 \cdot 7$ & 4 \\
\hline PEFR & $82 \cdot 0 \pm 20 \cdot 0$ & 6 & $84 \cdot 7 \pm 23 \cdot 2$ & 7 \\
\hline$V_{\max } 50$ & $71 \cdot 4 \pm 25 \cdot 6$ & 12 & $66 \cdot 6 \pm 28 \cdot 6$ & 6 \\
\hline$V_{\max } 25$ & $51 \cdot 9 \pm 24 \cdot 5$ & 12 & $47 \cdot 6 \pm 21 \cdot 9$ & 8 \\
\hline \multicolumn{5}{|l|}{ Post bronchodilator } \\
\hline $\mathrm{FEV}_{1}$ & $91 \cdot 9 \pm 19 \cdot 1$ & 6 & $90 \cdot 7 \pm 22 \cdot 1$ & 8 \\
\hline FVC & $104 \cdot 7 \pm 14 \cdot 3$ & 4 & $104 \cdot 3 \pm 19 \cdot 1$ & 5 \\
\hline PEFR & $91 \cdot 0 \pm 19.4$ & 5 & $92 \cdot 3 \pm 27 \cdot 4$ & 6 \\
\hline$V_{\max } 50$ & $86 \cdot 2 \pm 26 \cdot 1$ & 11 & $83 \cdot 5 \pm 35 \cdot 7$ & 7 \\
\hline
\end{tabular}

*All values apart from symptom scores are calculated as \% predicted for height. 


\section{Discussion}

Steroid aerosol therapy has greatly improved the management of asthma ${ }^{56}$ As budesonide is a new preparation of this type short-term efficacy and safety had to be established before longer trials could be performed. Budesonide was shown to be at least as effective as BDP in equal dosage, with most parameters showing a trend towards improvement with the new preparation.

Several of the children were considered to be well controlled on suboptimal doses of BDP before the trial, but improved after increasing to a 4-times daily schedule; this is often impossible to maintain for long periods particularly in children attending school and the twice daily dosage is therefore particularly useful. The optimal dose frequency of inhaled steroid preparations in asthma has never been clearly established as duration of action is unknown. It has been shown in an open crossover study that BDP in the same total daily dose was equally effective if administered in a 2- or 4-dose a day regimen. ${ }^{7}$

Only $8-10 \%$ of the dose delivered by pressurised aerosols actually reaches the lungs of patients with obstructive airways disease. ${ }^{8}$ This percentage may be increased by about $50 \%$ using a spacer inhaler. ${ }^{9}$ Furthermore, it has been shown that even if the inspiration is not co-ordinated with aerosol actuation, reasonable bronchodilatation can still be achieved using terbutaline delivered via an extension device. ${ }^{10}$ This mode of delivery may also aid peripheral deposition in the respiratory tract. ${ }^{11}$ One of the important effects of steroids in asthma is to inhibit the late reaction with occurs after allergen inhalation. ${ }^{12}$ This reaction is associated with prominent small airways obstruction, probably due to mucosal oedema and nonspecific inflammation. ${ }^{13}$ Thus placement of steroid medication in small airways may be important. A study comparing the same steroid aerosol administered with or without the tubespacer is required to test this hypothesis.

We feel that, although this trial did not show a statistically significant advantage of budesonide compared with BDP, the favourable trends suggest that further, longer-term studies are needed, par- ticularly in view of the advantages of the delivery system and the twice daily dose schedule.

\section{References}

1 Spicer J E, Cayton R M, Frame M H, Winsey N J P. Letter: Influence of tube-spacer on aerosol efficacy. Lancet 1980; ii: 1248.

2 Willey R F, Godden D J, Carmichael J, Preston P, Frame M H, Crompton G K. Comparison of twice daily administration of a new corticosteroid budesonide with beclomethasone diproprionate four times daily in the treatment of chronic asthma. $\mathrm{Br} J$ Dis Chest 1982; 76: 61-8.

3 Zapletal A, Motoyama E K, van de Woestijne K P, Hunt V, Bouhuys A. Maximum expiratory flow-volume curves and airway conductance in children and adolescents. J Appl Physiol 1969; 26: 308-16.

4 Polgar G, Promadhat V. Standard values. In: Pulmonary function testing in children. Philadelphia: Saunders, 1971: 87-212.

5 Godfrey S. In: Mygind N, Clark T J H, eds. Topical steroid treatment for asthma and rhinitis. London: Baillière Tindall, 1980: 123-36.

6 Taylor B, Norman A P. Betamethasone 17-valerate in childhood asthma. Acta Paediatr Scand 1975; 64: 234-40.

7 Mecoy R J, Laby B. Beclomethasone dipropionate in a twice daily treatment of asthma. Aust Fam Physician 1982; 9: 721-7.

8 Newman S P, Pavia D, Morén F, Sheahan N F, Clarke $S$ W. Deposition of pressurised aerosols in the human respiratory tract. Thorax $1981 ; 36: 52-5$.

9 Newman S P, Morén F, Pavia D, Little F, Clarke S W. Deposition of pressurized suspension aerosols inhaledo through extension devices. Am Rev Respir Dis 1981; 124: 317-20.

10 Ellul-Micallef E, Morén F, Wetterlin K, Hidinger K C.? Use of a special inhaler attachment in asthmatic children. Thorax 1980; 35: 620-3.

11 Morén F. Drug deposition of pressurised inhalation aerosols. I. Influence of actuator tube design. Int $J$ Pharmaceutics 1978; 1 : 205-12.

12 Booij-Noord H, Orie N G M, de Vries K. Immediate and late bronchial obstructive reactions to inhalation of house dust and protective effects of disodium cromoglycate and prednisolone. J Allergy Clin Immunol 1971; 48 : 344-54.

13 Warner J O. Significance of late reactions after bronchia challenge with house dust mite. Arch Dis Child 1976; 51 : 906-11.

Correspondence to $\mathrm{Dr} \mathrm{J} O \mathrm{O}$ Warner, Brompton Hospital, Fulham Road, London SW3 6HP.

Received 12 July 1982 